\title{
Work in Norway.
}

H. P. LIE.

WHE first time that leprosy is found mentioned in Norway is in some laws about the year 1000 A.D. In all probability the disease was introduced into this country several years before that time by the Norwegian Vikings, who had brought it home from their cruises to England, Scotland and Ireland. The disease was, in previous days, spread over the whole country, but its main seat has been along the coastal districts in south-west Norway, where the town of Bergen was for many centuries a commercial town of importance, with a bustling connection with the countries to the south as well as the west.

As is the case in other countries in Europe, leprosy in Norway reached its height in the Middle Ages, round about the year 1200 A.D., and in the thirteenth century two hospitals for the treatment of leprosy were constructed in Bergen. Hospitals for lepers have been built at other places in the country, but the ones in Bergen were the most important. Here also, about the year 1410, a big new hospital, St. Jorgen's (St. George's) Hospital, was erected, which exists to this very day, and is in all probability of somewhat similar construction, although it has several times been destroyed by fire, the last time in 1702, from which time the buildings date. Of the two old hospitals, one disappeared from history about 1394, whilst the other is mentioned as a leprosy hospital as late as 1514.

As in other parts of Europe, leprosy diminished considerably in Norway in the fifteenth and sixteenth centuries, and for this reason, St. Jorgen's Hospital in Bergen was, in 1545, turned into a general hospital, where only a small room was reserved for a few lepers. Leprosy was now looked upon as mastered, but contrary to supposition in Norway, leprosy in the country increased, although very slowly, in the seventeenth and eighteenth centuries. Probably there was a slight decrease around the year 1800, but in the nineteenth century it made an unpleasant and rapid increase. The number of cases at St. Jorgen's Hospital, where by far the greater number were lepers, gives a good idea of the conditions. Whilst there were only 58 patients in 1720 , there were 138 in 1754, 94 in 1808, and as many as 152 lepers in 1839.

A new era with regard to leprosy in Norway commenced with the year 1839. The spread of the disease aroused great 
attention among private parties as well as the government. The necessity for building more hospitals was discussed, and the famous leprologist Danielsen commenced his scientific investigations on leprosy with support from the government. In 1847, Danielsen and Boeck's famous work "Om Spedalskhed " (On Leprosy) presented to us a lucid clinical picture which medical science had, up to this time lacked, and with their pathological, anatomical and physiological chemical researches, formed the basis of modern scientific leprosy research. The campaign against this terrible disease was now taken up from a legislative, as well as administrative point of view, and a number of new leprosy hospitals were erected. Lungegaard Hospital was built, containing 80 beds, where Danielsen continued his scientific investigations, and in particular tried to discover remedies for the cure of the disease. In 1857, "Pleiestiftelsen for spedalske nr. 1" (Nursing Home for lepers, No. 1) was built, capable of taking 280 sufferers. Both of these hospitals were erected in Bergen. In 1861, the old Reknes Hospital, near Molde, dating from 1713, was enlarged so that it contained 160 beds. And the same year, the new Reitgjerdets Pleiestiftelse for spedalske (Reitgjerdets Nursing Home for Lepers) was opened near Trondhjem, in which there were 240 beds.

The reason that so many hospitals were found to be necessary was on account of the alarming manner in which the disease had spread. Thus, in 1856, there must have been at least 2,858 lepers among a population of just about one and a-half million.

In ancient times and the Middle Ages, we know that leprosy was looked upon as an infectious disease, and all to whom life and health were dear, took great care to avoid coming into contact with those suffering from this complaint. But as the disease diminished in Europe, this conception vanished little by little, and also the dread of intercourse with lepers. The general opinion held was that the disease spread hereditarily. This opinion was also supported by Danielsen and Boeck. According to their opinion, leprosy was an inheritable dyscrasia of the blood. The theory with regard to infection had always had some few supporters, and from the commencement of the last century, their numbers began to increase. In 1870 Armauer Hansen became a keen and prominent protogonist of the theory of contagion, and since he, in 1873, discovered the leper bacillus, this hypothesis has gained prominence, and thus formed the scientific basis for combating leprosy. As early as 1850 , however, the Norwegian Government had decided on several important 
sanitary measures. In 1854 they nominated a special physician, the Chief Medical Officer for Leprosy in Norway, who had to devote himself solely to the study of leprosy among the people, and to submit proposals for the combating of the disease. In 1857, so-called Boards of Health (Sundhetskommissioner) were established in the districts where leprosy was prevalent. By the Norwegian sanitary law of 1860, the task of these Boards of Health was increased to comprise not only leprosy, but all diseases and conditions which were of moment for the health of the people. These Boards of Health which exist to this very day, are organized in the following manner:

Norway is divided up into rather more than 700 small administrative districts or municipalities, which are called " Herreder." They are governed in a democratic manner, and have a well-organized self-government, which in but a comparatively few cases are restricted by government intervention. The rulers of these municipalities, the District Corporations (Herredstyre) in the country districts, and Town Council (Bystyret) in the towns, are elected from among and by the inhabitants of the towns or districts. In the country, these district corporations form the Health Board, together with the official physician, the physician acting in all cases as the President of the Board of Health. In the towns, the Health Boards consist of a number of specially elected persons, who are not in all cases members of the Town Council. In the towns, likewise, the official physician-the Town Medical Officer of Health-is in all cases the Board's President.

There is always an intimate co-operation in all questions touching leprosy, between the Boards of Health and the Chief Medical Officer for leprosy. With regard to governmental measures against leprosy, there exists a special act, namely, the act of June 6 th, 1885, regarding isolation of lepers. In practice, the combating of leprosy and the control of lepers is carried out in the following manner :

In all municipalities where leprosy has existed or still persists, the President of the local Board of Health keeps an exact record of all sufferers, stating the form and outbreak of the disease, the birth-place of the sufferer, and the place or places of residence, together with the sanitary conditions of the place, conditions with regard to family and relatives, information regarding the possible cause of the disease, such as intercourse with other lepers, etc. All sufferers are examined by the President of the Board of Health at least once a year, of ten accompanied by the Chief Medical Officer 
for leprosy, who, in the beginning of each year receives from the Presidents of the Boards of Health, a report regarding the sufferers' condition and of the sanitary conditions in their localities. If changes of importance occur in the condition of the patient, or if new or suspicious cases of leprosy appear, the President of the Board of Health concerned immediately sends a report on the matter to the Chief Medical Officer for leprosy, who, as soon as possible, makes further investigations regarding the conditions, together with the physician of the district, and draws up suggestions for the Board of Health as to what ought to be done. The Chief Medical Officer for leprosy has, as a matter of fact, only an advisory and inspecting, but not decisive authority. This always rests with the Board of Health. Injunctions on the sufferer or his surroundings are not legal and binding before they have been acknowledged by the Board of Health. At the meetings where these questions are discussed, the Chief Medical Officer for leprosy may be present if desirable, in order to supply further expert elucidation on such questions as the Board of Health might require further information about. If the Boards of Health do not take the Chief Medical Officer's advice, or if they act directly contrary to the law, the Chief Medical Officer must apply to the governmental department, to which the Boards of Health appertain, about the matter. The Chief Medical Officer stands in direct connection with, and directly under the same department. According to the aforementioned act of June 6 th, 1885 , poor persons suffering from leprosy must not be "laid," i.e., they must not be removed from place to place for natural maintenance. Pauper lepers who are cared for by the municipality ought, as a rule, to be admitted to hospital, where the State bears all expenses with regard to nursing and maintenance. Lepers other than paupers may be instructed by the Board of Health to live in satisfactory isolation from their surroundings. With regard to the decisions of the law about isolation, exception is made in the case of married couples, who wish to live together. If, however, the Board of Health find that a leper ought to be sent to hospital, married couples may thereby be separated. The Board's decisions with regard to such a step must be submitted to the parish parson for his opinion, and thereafter receive the approbation of the Superior Magistrate (Sheriff), before legal and binding rights with regard to the leper may be used. The general rule is that the leper is removed as soon as possible to hospital. This may take place immediately, provided that the patient is willing, and in most cases he is willing, when he realizes the dangers of living at home, 
and the advantages of hospital treatment. If the patient be unwilling to go to hospital, he receives a number of instructions that aim at isolating him from the surroundings in a satisfactory manner. If the sufferer, after repeated instructions from the Board of Health does not observe the precautions given him, the Board of Health may transport him to hospital against his wish with the help of the police. This method of procedure has, however, only rarely been found necessary.

In certain cases, small and specially built houses have been erected for the sufferer, so that he could continue to live at home. If a nodular case be not sent to hospital, he must have his own retreat where he sleeps and eats, have his own eating utensils, clothes and bedclothes, which must all be cleaned and washed separately. If there be any possibility that leprosy bacilli may be spread through feces or urine, such must then be disinfected with lime or similar preparation. The patient may move about in the open if he so wishes, but it is strictly forbidden to take meals or to sleep at other people's houses. In the case of anæsthetic cases, the same methods of procedure are observed as for nodular leprosy, provided that the patients are early cases, and that it might be supposed that the leprosy bacilli were excreted through the spots on the skin, or from the mucous membrane affections. In old cases without spots or affection of the mucous membrane, where one might assume that bacilli were not excreted at all, or only in a very slight degree, no compulsory removal to hospital has been employed, but the person concerned has lived by himself, and been under control in the home. The Board of Health's control is necessary, as new outbreaks of leprosy may occur after many year's standstill.

If the leper, who has had a family to support be admitted to hospital, the government has of late, granted a small sum of money annually for the support of the family, so that they should not want as long as the bread-winner lived. It goes without saying that the hospitals have at all times been ready to admit any leper, who, for one reason or another, wished to be admitted, even if he could have remained at home without being any particular danger to those around him. Such cases have also always received free maintenance in the governmental hospitals.

During transport of lepers, precautions have, as far as possible, been taken to isolate the most infectious cases, whilst in the less dangerous cases it has been considered sufficient to thoroughly clean the sleeping berth used by the patient. 
When a leper has been admitted to hospital, or dies in his home, both his clothes and residence shall be disinfected in such manner as the Board of Health may consider necessary in each individual case. As a rule, the occupied room or rooms are disinfected in the same manner as that undertaken after other infectious diseases; in some cases it has been demanded that the rooms shall be painted all over. If disinfection be neglected after leprosy, such offence is punishable.

In the leprosy hospitals, which have fairly big areas at their disposal for the patients, they may receive visits from relations and friends. The sufferers may also have a certain amount of liberty outside the hospital, but under control, especially in the case of those suffering from nodular leprosy. No leper is permitted to take a meal, or sleep outside the hospital, without special leave.

In previous days, some lepers left the hospital and went home without leave. In order to prevent this, it was decided to allow such patients as suffered greatly from nostalgia, to pay a short visit to their homes, under control. No escapes from the hospital have taken place of latter years.

From the accompanying Tables I and II, one will be able, without further explanation, to follow the course of leprosy in Norway from the year 1856 and up to the present time.

TABle I.

Figures in Norway.

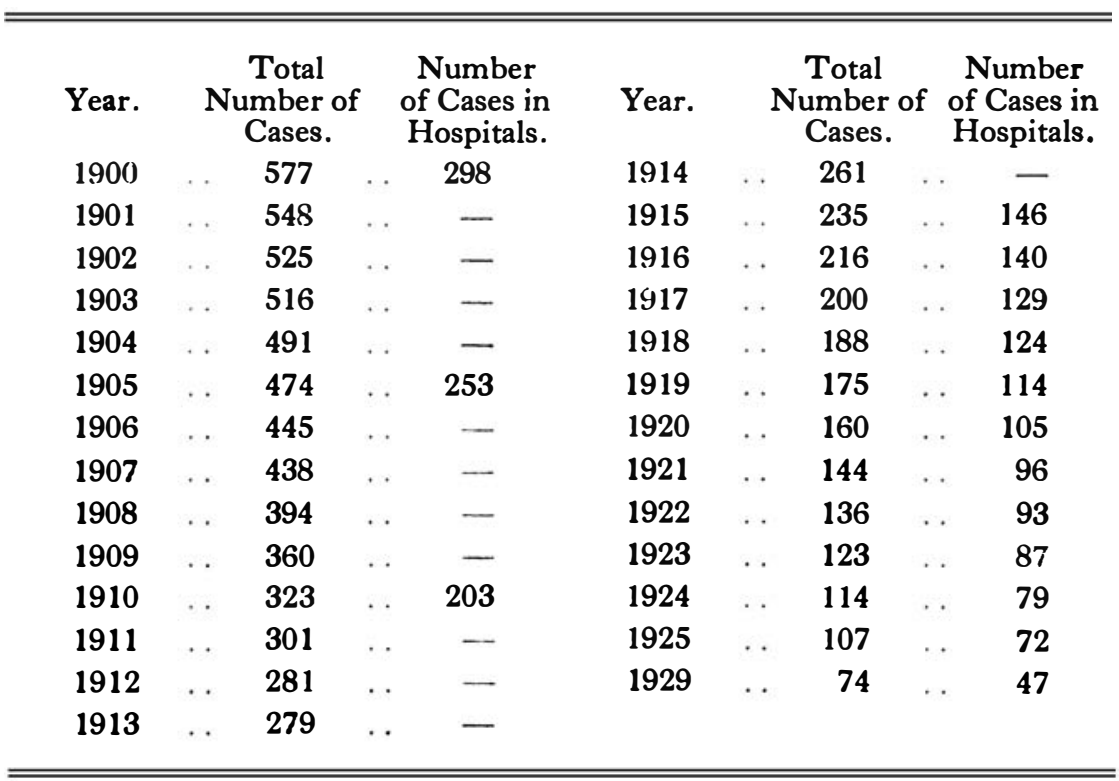


TABle II.

CoURSE of Leprosy in Norway from 1856 to 1929.

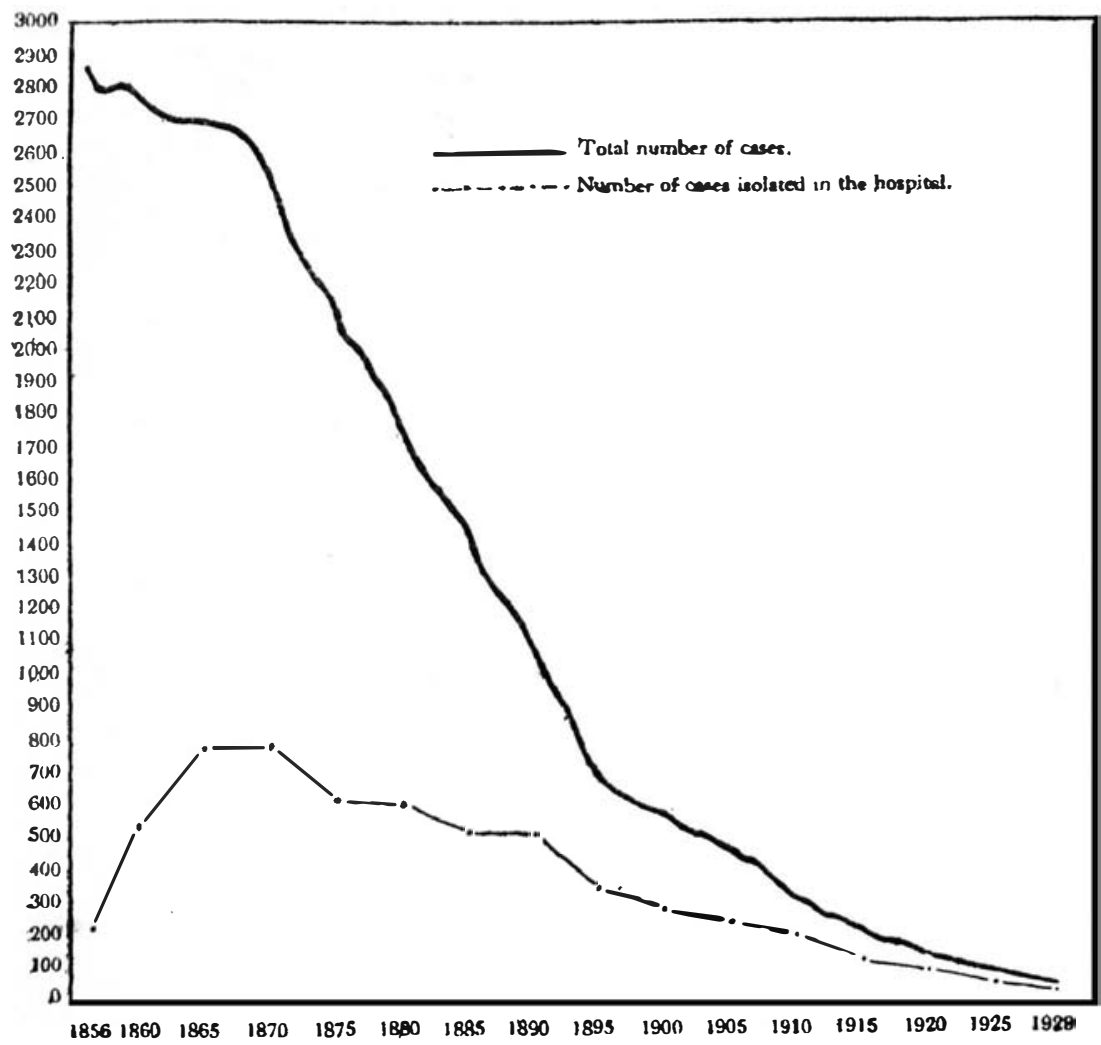

As the disease has diminished so greatly and evenly, there is good hope that we are within measurable distance of seeing it disappear in Norway. We can, however, not be quite sure of its disappearance until 25 or 30 years have elapsed since the last endemic case died off, or is quite isolated. Exact investigations in latter years have proved that leprosy, at any rate in this country, may have a long incubation period, and it may also take a very long time-15, 20 and up to 27 years after the last infection, before a case comes under the notice of the Boards of Health and their control. This especially concerns the less severe cases of maculo-anæsthetic leprosy. 